\title{
Farklı mikrobiyal gübrelerin boysenberry çeliklerinin köklenmesi üzerine olan etkileri
}

\section{Effects of different microbial fertilizers on rooting of boysenberry cuttings}

\author{
Sevinç ŞENER ${ }^{1}$ (D) Canan Nilay DURAN ${ }^{2}$ (D) \\ ${ }^{1}$ Akdeniz Üniversitesi, Ziraat Fakültesi, Bahçe Bitkileri Bölümü, Antalya, Türkiye \\ ${ }^{2}$ Akdeniz Üniversitesi, Fen Bilimleri Enstitüsü, Bahçe Bitkileri Anabilim Dalı, Antalya, Türkiye \\ Sorumlu yazar (Corresponding author): S. Şener, e-posta (e-mail): ssener@akdeniz.edu.tr \\ Yazar(lar) e-posta (Author e-mail): cananilay07@gmail.com
}

\section{MAKALE BİLGİSİ}

Alınıs tarihi 11 Mart 2020

Düzeltilme tarihi 16 Ekim 2020

Kabul tarihi 20 Ekim 2020

\section{Anahtar Kelimeler:}

Bacillus subtilis

Köklenme

Lactobacillus spp.

Trichoderma harzianum

\begin{abstract}
ÖZ
Böğürtlen antioksidanlar ve bazı pigmentler bakımından zengin olması sebebiyle insan sağlığ açısından öneme sahip, farklı şekillerde değerlendirilebilen, ekonomik değeri yüksek bir meyve türüdür. Ticari böğürtlen yetiştiriciliğinde çeliklerinin köklendirilmesinde genellikle sentetik hormonlar kullanılmakta ve organik tarımda kullanılabilecek alternatif preparatların araştırılması önem arz etmektedir. Bu çalışma farklı mikrobiyal gübrelerin boysenberry çeliklerinin köklenmesi üzerine olan etkisinin araştırılması amacıyla, köklendirme için uygun koşulların sağlandığı sisleme serasında yürütülmüştür. Deneme deseni tesadüf parselleri deneme desenine göre dört tekrarlamalı olarak kurulmuștur. Calıșmada bitkisel materyal olarak boysenbery (Rubus loganbaccus $\times$ Rubus baileyanus Britt) çelikleri kullanılmıştır. Çalışmada ayrıca ticari firmalardan temin edilen SimBacil (\%2, \%4, \%8), SimDerma (5 g, 10 $\mathrm{g}, 20 \mathrm{~g})$, OrgaStar $(\% 2, \% 4, \% 8)$ isimli preparatların 3 farklı dozu ve kontrol uygulaması yer almıştır. Deneme boyunca çeliklerde haftalık olarak yaprak sayısı (adet), gövde çapı (mm) ve sürgün uzunluğu $(\mathrm{cm})$ ölçümleri kaydedilmiș, deneme sonunda ise köklenen çeliklerde kök sayısı (adet), kök uzunluğu (cm), ve kök ağırlığı (g) ölçümleri belirlenmiştir. Elde edilen sonuçlar değerlendirildiğinde, mikrobiyal gübrelerin çeliklerinin köklenmesi üzerine kontrol uygulamasına göre önemli düzeyde etki ettiği tayin edilmiştir. Deneme neticesinde, en yüksek ortalama kök uzunluğu $19.47 \mathrm{~cm}$ ile $\% 8$ SimBacil uygulamasında, kök ağırlı̆ğ $18.42 \mathrm{~g}$ ile \%4 OrgaStar uygulamasında, kök sayısı ise 16.00 ile $20 \mathrm{~g}$ SimDerma uygulamasinda belirlenmiștir. Çalışma neticesinde organik sertifikalı gübrelerin böğürtlen çeliklerinin köklendirilmesinde kullanılabileceği önerilmektedir.
\end{abstract}

\section{ARTICLE INFO}

Received 11 March 2020

Received in revised form 16 October 2020 Accepted 20 October 2020

\section{Keywords:}

Bacillus subtilis

Rooting

Lactobacillus spp.

Trichoderma harzianum

\section{ABSTRACT}

Blackberry is a kind of fruit that can be evaluated in different ways and important for human health because of antioxidants and pigments content. Synthetic hormones are generally used for rooting in commercial blackberry cultivation and it is important to investigate alternative preparations that can be used in organic farming. This study was carried out in the greenhouse where a mist propagation and suitable conditions for rooting were provided, to investigate the effect of different microbial fertilizers on rooting of boysenberry cuttings. The experiment was established in randomized plots experimental design with 4 replications. In the study, cuttings of boysenberry (Rubus loganbaccus $\times$ Rubus baileyanus Britt) were used as plant material. In the study, control application and 3 different doses of preparations named SimBacil $(2 \%, 4 \%$, $8 \%$ ), SimDerma (5 g, $10 \mathrm{~g}, 20 \mathrm{~g})$, OrgaStar $(2 \%, 4 \%, 8 \%)$, obtained from commercial companies were used. Number of leaves, stem diameter and length of the cuttings were recorded weekly, root number, root length and root weight measurements were determined at the end of the experiment. At the end of the study, it was determined that microbial fertilizers had a significant effect on the rooting of blackberry cuttings compared to control application. As a result, the highest average root length determined in $8 \%$ SimBacil $(19.47 \mathrm{~cm})$, root weight was determined in $4 \%$ OrgaStar (18.42 g) and root number was determined in $20 \mathrm{~g}$ SimDerma (16.00 number/plant) application. As a result, it is suggested that organic certified fertilizers can be used in rooting blackberry cuttings. 


\section{Giriş}

Rubus cinsi yaklaşık 740 tür ile, bitkiler aleminde en fazla türe sahip olan cinslerden birisidir (Gu ve ark. 1993). Bögürtlen Rosaceae familyasının, Rubus cinsinin Eubatus alt cinsine girmekte ve Rubus fruticosus, Rubus discolar ve Rubus laciniatus türleri bulunmaktadır (Aydın 2008; Karakoç 2011). Çalımsı, dik, yarı dik veya sürünücü formlarda ve çoğu çeşidi dikenli olabilen bögürtlen hem lezzetli meyvelere sahip olması hem de zengin besin içeriği sebebiyle birçok ülkede ticari olarak yetiştirilmektedir (Kefayeti ve ark. 2019). Anavatanı Güney, Batı ve Orta Avrupa olan bögürtlenin kültür çeşitlerinin birçoğu Amerika ve Avrupa'da yabani olarak yayılım göstermektedir (Jennings ve ark. 1990; Hummer ve Janick 2007). Son yıllarda insan sağlığı ile beslenme arasındaki ilişkiler üzerinde sıça durulmakta ve taze meyve sebze tüketiminin önemi vurgulanmaktadır. Taze ve işlenmiş olarak farklı şekillerde tüketim olanağ 1 bulunan, vitamin, lif, antioksidanlar ve fenolikler bakımından zengin olan böğürtlen beslenme ve insan sağlığı açısından önem taşımaktadır (Siriwoharn ve ark. 2004; Srivastava 2009). Bögürtlen günlük diyette tüketilmesi önerilen (Diaconeasa ve ark. 2014), dünyada önemli miktarlarda üretilen (Strik ve ark. 2008) bir meyve türüdür. Türkiye, Rubus türleri açısından zengin genetik kaynaklara sahip olmasına rağmen, ülkemizde bögürtlen yetiştiriciliği açısından istenilen ticari potansiyele ulaşılamamıştır (Kurt ve ark. 2003). İlk olarak 1960'lı yıllarda başlamış olan bögürtlenle ilgili adaptasyon çalışmaları, gerek böğürtlen meyvesinin içerdiği biyoaktif bileşikler ve bunların insan sağlığı açısından faydaları nedeniyle, gerekse farklı tüketim olanaklarının yaratmış olduğu ekonomik avantajlar sebebiyle hız kazanmıştır (Fidan ve ark. 1975; Ağaoğlu 1986; Okay 1998; Akbulut ve ark. 2003; Cangi ve İslam 2003; Kurt ve ark. 2003; Balc1 ve Keleş 2019). Günümüzde dünyanın en değerli ticari meyvelerinden biri haline gelen bu bitkinin ülkemizde de üretimi ve tüketimi yıldan yıla artmaktadır (Akın ve ark. 2016). Türkiye'de 2807 da alanda yaklaşı 2540 ton bögürtlen üretimi yapılmakta olup, üretimin \%82'si Doğu Marmara Bölgesinde yapılmaktadır (TÜİK 2020). Birçok meyve türünde olduğu gibi bögürtlende de üretim değerlerinin artması sağlıklı ve kolay elde edilebilen fidanların üretimi ile yakından ilişkilidir. Sürgünleri tek bir kökten oluşan böğürtlenler, genellikle vejetatif olarak çelikle çoğaltılmaktadır. Çelikle çoğaltmada başarı, köklenmenin genetik potansiyeli, ana bitkinin fizyolojik koşulları, çeliklerin alınma sezonu, hormonal denge, sıcaklık, 1şık ve nem gibi çeşitli faktörlerden etkilenebilmektedir (Soundy ve ark. 2008). Kök sistemi oluşturarak yeni bir bitki elde edilmeye çalışılan çelikle çoğaltma yönteminde, kök oluşumu oksin, etilen, sitokinin, indole butrik asit (IBA), indole asetik asit (IAA) gibi bitkisel hormonların varlığından ve düzeyinden etkilenebilmektedir. Bunun yanı sıra besin elementleri de yeni kök oluşumu üzerine etki edebilmektedir (Hartman ve Kester 1974; Geneve ve Heuser 1983; Yıldız 2001). Meyve çeliklerinin köklendirilmesi amaciyla genellikle köklenme etkisi sürekli olan IBA yoğun (1000-8000 ppm) veya seyreltik (10-250 ppm) dozlarda kullanılabilmektedir (Zenginbal ve ark. 2006). Vejetatif çoğaltmada çeliklerin köklenme oranlarının istenilen seviyede olmaması ve geniş alan gereksinimi gibi sorunlar yaşanabilmektedir (Najaf-Abadi ve Hamidoghli 2009). Çelikle çoğaltma yöntemi ile ilgili yapılmış olan çalışmalar incelendiğinde, genellikle hormon uygulamasının kullanıldığ göze çarpmaktadır (Cooper 1936; McGuire ve Sorensen 1966; Edizer 2011; Campagnolo ve Pio 2012; Öztürk ve ark. 2016; Saraçoğlu ve ark. 2016; Debner ve ark. 2019). Günümüzde üretim ve tüketim değerleri hızla artan organik tarım (Greene
2018) gibi sentetik kimyasalların kullanılmadığı bitkisel üretim metotlarında kullanılabilecek alternatif materyallerin ve yöntemlerin araştırılması önem arz etmektedir. Ülkemizin birçok bölgesi böğürtlen yetiştiriciliği için uygun ekolojik koşullara sahip olmasına rağmen bu konuda yapılan çalışmalar literatürde hayli sınırlı sayıda yer almaktadır. Bu sebeple bu çalışma, organik sertifikalı 3 farklı mikrobiyal bitki büyüme düzenleyicisinin ve bunların 3 farklı dozunun (SimBacil; \%2$\% 4-\% 8$, SimDerma; 5 g-10 g-20 g, OrgaStar; \%2-\%4-\%8) boysenberry çeliklerinin köklenme başarıları üzerine olan etkilerini belirlenmek amacıyla gerçekleştirilmiştir.

\section{Materyal ve Metot}

$\mathrm{Bu}$ çalışma, bazı organik sertifikalı bitki büyüme düzenleyicilerinin boysenberry çeliklerinin köklenmesi üzerindeki etkisini gözlemlemek için planlanmıştır. Çalışmada bitkisel materyal olarak boysenbery (Rubus loganbaccus $\times$ Rubus baileyanus Britt) çelikleri kullanılırken, mikrobiyal gübre olarak ticari firmalardan temin edilen, 'SimBacil','SimDerma' ve 'OrgaStar' isimli preparatlar kullanılmıştır. SimBacil içeriğinde canlı Bacillus subtilis kültürünün yer aldığı üretici firma tarafindan beyan edilmektedir. SimDerma ise doğal bir Trichoderma harzianum izolatı içeren mikrobiyal bir gübredir. OrgaStar isimli preparat ise, üretici firma tarafından çeşitli katı organik maddelerin fermentasyonu sonucu oluşan, organik madde, humik-fulvik asit ve yararlı bakterileri içeren mikrobiyal gübre olarak tanımlanmaktadır.

Araştırma 2018-2019 yılları arasında Akdeniz Üniversitesi Ziraat Fakültesi Bahçe Bitkileri Bölümü Uygulama Arazisinde bulunan sisleme sistemine sahip çoğaltma ünitesinde, perlit ortamında yürütülmüştür. Çalışmada SimBacil (\%2, \%4, \%8), SimDerma $(5 \mathrm{~g}, 10 \mathrm{~g}, 20 \mathrm{~g})$ ve OrgaStar (\%2, \%4, \%8) preparatlarının 3 farklı dozları ve kontrol uygulaması yer almıştır. Deneme deseni tesadüf parselleri deneme desenine göre dört tekrarlamalı olarak kurulmuş olup, her tekerrürde 10 çelik kullanılmıştır. $\mathrm{Bu}$ amaçla, 400 adet çelik farklı uygulamalara tabi tutulduktan sonra sisleme ünitesinde 4 hafta süreyle köklendirme amaciyla bekletilmiştir. SimBacil, SimDerma ve OrgaStar preparatlarının belirtilen dozlarda hazırlanan solüsyonlarında ilkbahar taze çelikleri $5 \mathrm{dk}$ süre ile bekletilmiştir (Aşan 2017). Kontrol uygulamasında çelikler 5dk süreyle saf suya daldırılmıştır. Uygulamaların etkinliğinin belirlenmesi amaciyla deneme boyunca çeliklerde haftalık olarak yaprak sayısı (adet), gövde çapı $(\mathrm{mm})$ ve sürgün uzunluğu $(\mathrm{cm})$ ölçümleri kaydedilmiş, deneme sonunda ise köklenen çeliklerde yaprak sayısı (adet), kök sayısı (adet), kök uzunluğu (cm), sürgün uzunluğu (cm), gövde çapı $(\mathrm{mm})$ ve kök ağırlığı (g) ölçümleri yapılmıştır.

Elde edilen veriler SPSS (23.0) paket programında istatistiksel değerlendirmeye tabi tutulmuş, uygulamalar arasındaki farklılıkları belirlemek için Duncan çoklu karşılaştırma testi kullanılmıştır.

\section{Bulgular ve Tartışma}

Elde edilen verilerin değerlendirilmesi sonucunda mikrobiyal gübre uygulamaları arasında istatistiksel anlamda önemli düzeyde farklıkların olduğu tespit edilmiştir.

Farklı mikrobiyal preparatların boysenberry çeliklerinin sürgün gelişimi üzerine olan etkileri Çizelge 1'de yer almaktadır. Sürgün çapı açısından farklı uygulamaların ve dozların önemli bir etkisinin olmadığı bununla birlikte en yüksek ortalama sürgün çapının SimDerma uygulamasının $10 \mathrm{~g}$ 
dozunda $(5.81 \mathrm{~mm})$, en düşük ise kontrol uygulamasında (3.75 $\mathrm{mm})$ tespit edildiği Çizelge 1'de görülmektedir. Sürgün uzunluğu bakımından ise en yüksek ortalama değerler SimDerma Uygulamasının $20 \mathrm{~g}$ dozu $(27.13 \mathrm{~cm})$ ile OrgaStar uygulamasının $\% 4$ uygulama dozunda $(27.00 \mathrm{~cm})$ tayin edilmiştir. Uygulamaların yaprak sayısı üzerine olan etkileri değerlendirildiğinde ise en yüksek sonucun OrgaStar uygulamasının \%4 uygulama dozunda (11.00 adet) belirlendiği görülmektedir. Bağçevli (2010) da benzer şekilde, Bioplin, Bioone, Endo Roots ve Vitormone isimli mikrobiyal içerikli ticari preparatlarının, asma çeliklerinin kök gelişimini ve bu çeliklerden elde edilen fidan gelişimini olumlu yönde etkilediğini bildirmiştir. Güneş (2015), 2 yaşlı Syrah/110R üzüm çeşidi fidanlarına farklı dozlarda Trichoderma harzianum $4 \mathrm{doz}\left(5 \mathrm{~g} \mathrm{l}^{-1}, 10 \mathrm{~g} \mathrm{l}^{-1}, 20 \mathrm{~g} \mathrm{l}^{-1}, 0 \mathrm{~g} \mathrm{l}^{-1}\right)$ ve Bacillus subtilis $4 \mathrm{doz}$ $(\% 2, \% 4, \% 8, \% 0)$ uyguladığı çalışma sonunda, Trichoderma harzianum' un $20 \mathrm{~g} \mathrm{l}^{-1}$ ' lik dozu ve Bacillus subtilis' in \%8' lik dozunun, bizim çalışmamızdan elde edilen sonuçlara benzer şekilde olumlu etkiler yaptığını bildirmiştir. Sonuç olarak mikrobiyal gübre uygulamalarının tüm dozlarının, kontrol parsellerine göre sürgün gelişimi parametreleri üzerine pozitif yönde katkı sağladığı kaydedilmiştir.

Boysenberry çeliklerinin farklı uygulamalardaki kök uzunluğu, kök ağırlığı ve kök sayısı verileri Çizelge 2'de verilmiştir. Çizelge 2 'de sunulan veriler incelendiğinde tüm uygulamalar arasında istatistiksel anlamda önemli düzeyde farklılıkların $(\mathrm{P}<0.05)$ tayin edildiği görülmektedir. En yüksek ortalama kök uzunluğu $19.47 \mathrm{~cm}$ ile SimBacil uygulamasının $\% 8$ 'lik dozunda tespit edilirken, en yüksek ortalama kök ağırlığg OrgaStar uygulamasının \%4'lük dozunda (18.42 g) belirlenmiştir. Kök sayısı bakımından ise en yüksek ortalama değer SimDerma preparatının 20 g uygulama dozunda (16 adet) tespit edilmiştir. Kınık ve Çelikel (2017) yapmış oldukları çalışmada Rosa canina L. çeliklerinin köklenmesi üzerine 10 farklı rizobakterinin (bitki gelişimini düzenleyen) ve IBA'nın $(1000 \mathrm{ppm})$ etkisini araştırmış, çalışma sonunda bakteri uygulamalarının köklenme oranı dışında, köklenme kalitesini (kök yumağı eni, kök boyu ve ana kök sayısı) artırdığını bildirmiştir. Bir diğer çalışmada ise Güler ve ark. (2017) Gemlik zeytin çeşidinin yarı odun çeliklerinin köklendirilmesi üzerine $1 \mathrm{ml} \mathrm{l}^{-1}$ Gabiokat uygulamalarının etkisi araştırmış ve çalışma sonunda Gabiokat uygulamasının kontrole göre köklenme oranını önemli düzeyde artırdığını bildirmişlerdir. Öztürk ve ark. (2016), Jumbo bögürtlen çeşidine ait çeliklerin köklenmesi üzerine IBA'nın farklı dozlarının $(0,1000,2000$ ve 3000 ppm) etkisini araştırmışlar ve en yüksek köklenme oranını 1000 ppm alt-üst IBA uygulamasında tayin etmişlerdir. Bitki çeliklerinin köklenmesinde ki başarının, köklendirmeyi teşvik etmek için kullanılan materyalin yanı sıra çelik alma zamanı ve yetiştirme koşulları farklılığından kaynaklanabileceği düşünülmektedir. Bunun yanı sıra bazı araştırmacılar yüksek yoğunluktaki bazal uygulamaların çeliklere zarar verebileceğini bildirmektedirler (Cooper 1936).

Çizelge 1. Farklı uygulamaların boysenberry çeliklerinin sürgün gelişimi üzerine etkileri.

Table 1. Effects of different applications on shoot development of boysenberry cuttings.

\begin{tabular}{|c|c|c|c|c|}
\hline Uygulamalar & Uygulama Dozu & Sürgün Uzunluğu (cm) & Yaprak Sayısı (adet) & Sürgün Çapı (mm) \\
\hline Kontrol & $\% 0$ & $24.72 a b c$ & $5.80 \mathrm{~b}$ & 3.75 \\
\hline \multirow{3}{*}{ SimBacil } & $\% 2$ & 18.38 bcd* $^{*}$ & $8.33 \mathrm{ab}$ & 4.71 \\
\hline & $\% 4$ & $25.10 \mathrm{ab}$ & $7.50 \mathrm{ab}$ & 4.85 \\
\hline & $\% 8$ & $21.45 \mathrm{abcd}$ & $9.75 \mathrm{ab}$ & 5.63 \\
\hline \multirow{3}{*}{ SimDerma } & $5 \mathrm{~g}$ & $19.23 \mathrm{bcd}$ & $9.25 \mathrm{ab}$ & 4.18 \\
\hline & $10 \mathrm{~g}$ & $16.57 \mathrm{~d}$ & $6.67 \mathrm{~b}$ & 5.81 \\
\hline & $20 \mathrm{~g}$ & $27.13 \mathrm{a}$ & $7.33 \mathrm{ab}$ & 5.25 \\
\hline \multirow{3}{*}{ OrgaStar } & $\% 2$ & $18.10 \mathrm{~cd}$ & $9.50 \mathrm{ab}$ & 5.45 \\
\hline & $\% 4$ & $27.00 \mathrm{a}$ & $11.00 \mathrm{a}$ & 5.46 \\
\hline & $\% 8$ & $21.25 \mathrm{abcd}$ & $8.10 \mathrm{ab}$ & 5.31 \\
\hline
\end{tabular}

*:Aynı harfle gösterilen ortalamalar arasındaki farklar $\mathrm{P}<0.05$ önem seviyesinde önemli değildir.

Çizelge 2. Farklı uygulamaların boysenberry çeliklerinin kök gelişimi üzerine etkileri.

Table 2. Effects of different applications on root development of boysenberry cuttings.

\begin{tabular}{|c|c|c|c|c|}
\hline Uygulamalar & Uygulama Dozu & Kök Uzunluğu (cm) & Kök Ağırlığg (g) & Kök Sayısı (adet) \\
\hline Kontrol & $\% 0$ & $10.00 \mathrm{~b}$ & $2.25 \mathrm{c}$ & $8.00 \mathrm{ab}$ \\
\hline \multirow{3}{*}{ SimBacil } & $\% 2$ & $17.55 \mathrm{ab}^{*}$ & $5.66 \mathrm{bc}$ & $12.00 \mathrm{ab}$ \\
\hline & $\% 4$ & $14.80 \mathrm{ab}$ & $6.3 \mathrm{bc}$ & $11.88 \mathrm{ab}$ \\
\hline & $\% 8$ & 19.47 a & $12.02 \mathrm{~b}$ & $11.25 \mathrm{ab}$ \\
\hline \multirow{3}{*}{ SimDerma } & $5 \mathrm{~g}$ & $14.50 \mathrm{ab}$ & $3.63 \mathrm{c}$ & $6.66 \mathrm{~b}$ \\
\hline & $10 \mathrm{~g}$ & $15.17 \mathrm{ab}$ & $2.64 \mathrm{c}$ & $10.00 \mathrm{ab}$ \\
\hline & $20 \mathrm{~g}$ & $13.67 \mathrm{ab}$ & $8.81 \mathrm{bc}$ & $16.00 \mathrm{a}$ \\
\hline \multirow{3}{*}{ OrgaStar } & $\% 2$ & $15.25 \mathrm{ab}$ & $4.73 \mathrm{c}$ & $7.00 \mathrm{~b}$ \\
\hline & $\% 4$ & $15.95 \mathrm{ab}$ & 18.42 a & $10.40 \mathrm{ab}$ \\
\hline & $\% 8$ & $14.60 \mathrm{ab}$ & $2.78 \mathrm{c}$ & $8.80 \mathrm{ab}$ \\
\hline
\end{tabular}

\footnotetext{
*:Aynı harfle gösterilen ortalamalar arasındaki farklar $\mathrm{P}<0.05$ önem seviyesinde önemli değildir.
} 


\section{Sonuç}

Organik sertifikalı 3 mikrobiyal gübrelerin ve bunların farklı dozlarının (SimBacil, SimDerma, OrgaStar), boysenberry çeliklerinin köklenmesi üzerine olan etkilerinin araştırıldığı bu çalışma sonunda, çeliklerin büyüme ve gelişme parametreleri (yaprak say1s1, gövde çap1 ve sürgün uzunluğu) ortalama değerleri ile kök parametreleri (kök sayısı, kök uzunluğu ve kök ağırlığı) ortalama değerlerinin uygulamalara ve dozlara göre farklılık gösterdiği belirlenmiştir. Bununla birlikte böğürtlen çeliklerinin köklendirilmesinde mikrobiyal gübre kullanımının sentetik hormon kullanımına alternatif olabileceği düşünülmektedir. Araştırma bulgularının değerlendirilmesi neticesinde bögürtlen çeliklerinin köklendirilmesinde SimBacil preparatı için \%8, SimDerma için $20 \mathrm{~g}$ ve OrgaStar preparatı için \%4'lük uygulama dozları tavsiye edilmiştir.

\section{Kaynaklar}

Ağaoğlu YS (1986) Üzümsü Meyveler. 2. Bask1, Ankara Üniversitesi Ziraat Fakültesi Yayınları, Ankara.

Akbulut M, Kaplan N, Macit İ, Özdemir C (2003) Samsun Çarşamba Ovası Koşullarına uygun böğürtlen çeşitlerinin belirlenmesi. Ulusal Kivi ve Üzümsü Meyveler Sempozyumu. Ordu, Türkiye. s. 357360.

Akın M, Eyduran SP, Ercisli S, Kapchina-Toteva V, Eyduran E (2016) Phytochemical profiles of wild blackberries, black and white mulberries from southern Bulgaria. Biotechnology Biotechnological Equipment 30: 899-906.

Aşan H (2017) Asma fidanı üretiminde aşılı çeliklere biyo-ajan uygulamalarının aşıda başarı oranı, fidan randımanı ve kalitesine etkileri. Yüksek Lisans Tezi, Namık Kemal Üniversitesi, Fen Bilimleri Enstitüsü, Tekirdağ.

Aydın E (2008) Bazı ahududu ve böğürtlen çeşitlerinin Trabzon (Hayrat) ekolojik koşullarına adaptasyonu üzerine bir araștırma. Yüksek Lisans Tezi, Ordu Üniversitesi Fen Bilimleri Enstitüsü, Ordu.

Bağçevli A (2010) Bazı simbiyotik mikroorganizma karışımı uygulamalarının farklı asma anacı çeliklerinde köklenme ve bitki gelişimi üzerine etkileri. Doktora Tezi, Selçuk Üniversitesi Fen Bilimleri Enstitüsü, Konya.

Balcı G, Keles H (2019) Bazı böğürtlen çeşitlerinin Yozgat ekolojisinde adaptasyon yeteneklerinin belirlenmesi. Adnan Menderes Üniversitesi Ziraat Fakültesi Dergisi 16: 45-52.

Campagnolo MA, Pio R (2012) Rooting of stems and root cutting of blackberry cultivars collected in different times, cold storage and treatment with IBA. Ciência Rural 42: 232-237.

Cangi R, İslam A (2003) Bazı ahududu çeşitlerinin Ordu yöresine adaptasyonu (2000-2002 Gözlem Sonuçları). Ulusal Kivi ve Üzümsü Meyveler Sempozyumu. Ordu, Türkiye, s. 344-347.

Cooper WC (1936) Transport of Root- Forming Hormone in Woodycuttings. Plant Physiology 11: 779-793.

Debner AR, Hatterman-Valenti H, Takeda F (2019) Blackberry propagation limitations when using floricane cuttings. HortTechnology 29: 276-282.

Diaconeasa Z, Florica R, Rugınă D, Lucıan C, Socacıu C (2014) HPLC/PDA-ESI/MS identification of phenolic acids, flavonol glycosides and antioxidant potential in blueberry, blackberry, raspberries and cranberries. Journal of Food and Nutrition Research 2: 781-785.

Edizer AS (2011) Jumbo böğürtlen (Rubus fructicosus L.) çeşidinde vejetatif çoğaltma potansiyelinin belirlenmesi. Yüksek Lisans Tezi, Gaziosmanpaşa Üniversitesi Fen Bilimleri Enstitüsü, Tokat.

Fidan Y, Ağaoğlu, S, Çelik H (1975) Ankara şartlarında yetiştirilen muhtelif ahududu ve böğürtlen çeşitlerinin bazı özeliklerinin tespiti üzerine bir araştırma. Ankara Üniversitesi Ziraat Fakültesi Dergisi 25: 905-917.

Geneve RL, Heuzer CV (1983) The relationship between ethephon and auxsin on adventitious root initiation in cuttings of Vigna radiata $\mathrm{L}$. Journal of the American Society for Horticultural Science 108: 330333.

Greene C, Hitaj C, Bowman M, Cooke B, Ferreira G, Carlson A, McBride W (2018) The Outlook for Organic Agriculture. No. 2072-2018-3278, United States Department of Agriculture, USA.

Gu Y, Li WL, Jin W, Zhao CM (1993) Evaluation of Rubus germplasm resources in China. Acta Horticulturae 352: 317-324.

Güler Z, Özkaya MT, Dousti S (2017) Gemlik zeytin çeşidinin yarı odun çeliklerinin köklendirilmesi. Zeytin Bilimi 7: 1-4.

Güneş N (2015) Organik bağcılıkta syrah üzüm çeşidi fidanlarına farklı dozlarda uygulanan Trichoderma harzianum ve Bacillus subtilis' in tutma ve gelişme üzerine etkileri. Yüksek Lisans Tezi, Namık Kemal Üniversitesi, Fen Bilimleri Enstitüsü, Tekirdağ.

Hartman HT, Kester DE (1974) (Çevirenler: N. Kaşka, M. Yılmaz). Bahçe Bitkileri Yetiştirme Tekniği. 2. Baskı, Ankara Üniversitesi Basımevi, Ankara.

Hummer KE, Janick J (2006) Rubus iconography: Antiquity to the Renaissance. In XXVII International Horticultural CongressIHC2006: Global Horticulture: Diversity and Harmony, an Introduction to IHC2006 759. pp. 89-106.

Jennings DL, Daubeny HA, Moore JN (1990) Blackberries and raspberries (Rubus). Acta Horticulturae 290: 331-389.

Karakoç D (2011) Orta ve Doğu Karadeniz bölgesi doğal florasındaki böğürtlen genotipleri arasındaki biyoçeşitliliğin moleküler belirteçlerle saptanması. Yüksek Lisans Tezi, Gaziosmanpaşa Üniversitesi Fen Bilimleri Enstitüsü, Tokat.

Kefayeti S, Kafkas E, Ercisli S (2019) Micropropagation of 'Chester thornless' blackberry cultivar using axillary bud explants. Notulae Botanicae Horti Agrobotanici Cluj-Napoca 47: 162-168.

Kınık E, Çelikel FG (2017) Effects of plant growth promoting bacteria and auxin on cutting propagation of rosa canina L. Turkish Journal of Agriculture-Food Science and Technology 5: 1714-1719.

Kurt H, Turan A, Ruşen M (2003) Bazı ahududu ve böğürtlen çeşitlerinin giresun ekolojik koşullarına adaptasyonu. Ulusal Kivi ve Üzümsü Meyveler Sempozyumu. Ordu, Türkiye, s. 365-371.

McGuire JJ, Sorensen DC (1966) Effect of terminal applications of IBA on rooting of woody ornamental plants. Proceedings of the International Plant Propagator's Society 16: 257-260.

Najaf-Abadi AJ, Hamidoghli Y (2009) Micropropagation of thornless trailing blackberry ('Rubus sp.') by axillary bud explants. Australian Journal of Crop Science 3: 191-194.

Okay AN (1998) Doğu Karadeniz Bölgesinde ahududu ve böğürtlen tarımı. Doğu Karadeniz Bölgesi Tarımsal ve Sosyo-ekonomik Problemlerinin Çözümleri Sempozyum ve Paneli. Türk Ziraat Yüksek Mühendisleri Birliği ve Vakfı Yayınları.

Öztürk ES, Çekiç Ç, Saraçoğlu O, Yıldız K (2016) Jumbo böğürtlen rubus fruticosus 1 çeșidinin odun çeliklerinde farklı IBA doz ve uygulama yöntemlerinin köklenme üzerine etkileri. Bahçe 45: 9399.

Saraçoğlu O, Oğuz Hİ, Yıldız K, Çekiç Ç (2016) Gf 677 ve Rootpac R anaçlarına ait odun çeliklerinin köklenmesi üzerine farklı IBA dozlarının etkisi. Bahçe 45: 623-656.

Siriwoharn T, Wrolstad RE, Finn CE, Pereira CB (2004) Influence of cultivar, maturity, and sampling on blackberry (Rubus L. Hybrids) Anthocyanins, polyphenolics and antioxidant properties. Journal of Agricultural and Food Chemistry 52: 8021-8031.

Soundy P, Mpati KW, du Toit ES, Mudau FN, Araya HT (2008) Influence of cutting position, medium, hormone and season on rooting of fever tea (Lippia javanica L.) stem cuttings. Medicinal and Aromatic Plant Science and Biotechnology 2: 114-116. 
Srivastava A (2009) Phenolic constituents of Georgia-grown blackberry cultivars: fractionation and characterization of their antioxidant, radical scavenging, and anti-inflammatory capacities. Doctoral Thesis, University of Georgia, Athens.

Strik BC, Clark JR, Finn CE, Banados MP (2008) Worldwide production of blackberries. Acta horticulturae 777: 209-217.

TÜİK (2020) Türkiye İstatistik Kurumu, Bitkisel Üretim İstatistikleri Veri Tabanı. http://tuikapp.tuik.gov.tr/bitkiselapp/bitkisel.zul Erişim 09 Ocak 2020.
Yıldız K (2001) Bazı meyve türlerinde odun çeliklerinin köklenmesi üzerine IBA, CEPA ve AVG'nin etkisi. Yüzüncü Yıl Üniversitesi Tarım Bilimleri Dergisi 11: 51-54.

Zenginbal H, Özcan M, Haznedar A (2006) Kivi (Actinidia Deliciosa, A. Chev.) odun çeliklerinin köklenmesi üzerine IBA uygulamalarının etkisi. Anadolu Tarım Bilimleri Dergisi 21: 40-43. 